Research Paper

\title{
Isoalantolactone Induces Reactive Oxygen Species Mediated Apoptosis in Pancreatic Carcinoma PANC-1 Cells
}

\author{
Muhammad Khan 1,2, Chuan Ding², Azhar Rasul'1, Fei Yi'1, Ting Li', Hongwen Gao', Rong Gao', Lili Zhong', \\ Kun Zhang ${ }^{1}$, Xuedong Fang ${ }^{1}$ and Tonghui $\mathrm{Ma}^{1,2}{ }^{\bowtie}$
}

1. Central Research Laboratory, Jilin University Bethune Second Hospital, Changchun 130041, P. R. China;

2. Membrane Channel Research Laboratory, Northeast Normal University, Changchun 130024, P. R. China.

$\triangle$ Corresponding author: Tonghui Ma, Central Research Laboratory, Jilin University Bethune Second Hospital, Changchun 130041, P. R. China. Tel: +86-431-88796667. Fax: +86-431-88796667. E-mail: math108@gmail.com

() Ivyspring International Publisher. This is an open-access article distributed under the terms of the Creative Commons License (http://creativecommons.org/ licenses/by-nc-nd/3.0/). Reproduction is permitted for personal, noncommercial use, provided that the article is in whole, unmodified, and properly cited.

Received: 2011.11.05; Accepted: 2012.03.22; Published: 2012.03.28

\begin{abstract}
Isoalantolactone, a sesquiterpene lactone compound possesses antifungal, antibacteria, antihelminthic and antiproliferative activities. In the present study, we found that isoalantolactone inhibits growth and induces apoptosis in pancreatic cancer cells. Further mechanistic studies revealed that induction of apoptosis is associated with increased generation of reactive oxygen species, cardiolipin oxidation, reduced mitochondrial membrane potential, release of cytochrome c and cell cycle arrest at S phase. N-Acetyl Cysteine (NAC), a specific ROS inhibitor restored cell viability and completely blocked isoalantolactone-mediated apoptosis in PANC-I cells indicating that ROS are involved in isoalantolactone-mediated apoptosis. Western blot study showed that isoalantolactone increased the expression of phosphorylated p38 MAPK, Bax, and cleaved caspase-3 and decreased the expression of $\mathrm{Bcl}-2$ in a dose-dependent manner. No change in expression of phosphorylated p38 MAPK and Bax was found when cells were treated with isoalantolactone in the presence of NAC, indicating that activation of these proteins is directly dependent on ROS generation. The present study provides evidence for the first time that isoalantolactone induces ROS-dependent apoptosis through intrinsic pathway. Furthermore, our in vivo toxicity study demonstrated that isoalantolactone did not induce any acute or chronic toxicity in liver and kidneys of CDI mice at dose of $100 \mathrm{mg} / \mathrm{kg}$ body weight. Therefore, isoalantolactone may be a safe chemotherapeutic candidate for the treatment of human pancreatic carcinoma.
\end{abstract}

Key words: Isoalantolactone; PANC-1; ROS; Apoptosis; NAC.

\section{Introduction}

Pancreatic cancer is the fourth most common cause of cancer-related deaths in United States [1]. Despite advancements in diagnosis, surgery, radiotherapy and chemotherapy, the overall 5 year survival rate remains less than 3 years while the median survival rate is about 6 months [2]. Surgical abscission remains the only option for long term survival of patients. However, difficulty in achieving early diagnosis and aggressive nature of this type of cancer limit the surgical operation to only about $10 \%$ patients. Therefore, the majority of pancreatic cancer patients are treated with chemotherapy [3]. Currently, gemcitabine (Gem) is the most effective chemotherapeutic drug for pancreatic cancer. However, even with this drug, the overall survival rate remains considerably low. Moreover, Gem is highly toxic to tumor cells as well as normal cells $[4,5]$. Several other cytotoxic and chemotherapy agents such as cisplatin, fluorouracil, 
docetaxel and irinotecan have been tested as single agent or in combination with gemcitabine for pancreatic cancer, however most of these studies failed to ameliorate overall patient survival compared to gemcitabine [3]. Furthermore, most of these drugs have been shown to cause severe hepatotoxicity [6]. As pancreatic cancer responds poorly to the existing conventional chemotherapy, therefore it is important to study the anti-pancreatic cancer mechanism using newly identified effective anticancer compounds that exhibit low toxicity on normal cells.

A number of recent reports indicated that phytochemicals targeting ROS metabolism can selectively kill the cancer cells by raising the level of ROS above a toxic threshold. As cancer cells contain higher level of endogenous ROS than normal cells, the toxic threshold can be easily achieved in cancer cells compared to normal cells $[7,8]$. In the present study, we performed high throughput screening of compound library from Chinese herbs, using pancreatic cancer cell line PANC-1, in the presence or absence of NAC, a specific ROS inhibitor. This screening method allowed us to identify anti-pancreatic cancer compounds targeting ROS metabolism. Isoalantolactone, a sesquiterpene lactone compound was identified as a potent inhibitor of pancreatic carcinoma cells during screening process. Sesquiterpene lactones are plant-derived compounds used in the manufacture of traditional medicines for the treatment of inflammatory diseases, headache and infections [9]. Over the past few years, a large body of pharmacological studies has provided convincing evidences of the anticancer property of sesquiterpene lactones against various human cancer cell lines [10, 11]. At present, several sesquiterpene lactone compounds are in cancer clinical trials against breast, colorectal, kidney, prostate, acute myeloid leukemia, acute lymphoblastic leukemia, and non small lung cancer treatment [10]. However, the anti-pancreatic cancer potential of sesquiterpene lactone compounds is not well studied.

Isoalantolactone is one of the major sesquiterpene lactone compounds, isolated from the roots of Anula helenium and possesses multiple biological activities including antibacteria, antifungal, antihelminthic and antiproliferative [12]. The above findings encouraged us to study the anti-pancreatic cancer potential of isoalantolactone as well as its toxicity on normal cells in vitro and hepatotoxicity and nephrotoxicity in vivo.

\section{Materials and Methods}

\section{Reagents}

Isoalantolactone (IALT) was purchased from
Tauto Biotech Co., Ltd. (Shanghai, China) and purity (> 99\%) was determined by HPLC. RNase A, Propidium iodide (PI), calcein acetoxymethylester (Calcein AM), Hoechst 33258, 10-Nnonyl Acridine Orange (NAO), Dimethyl Sulfoxide (DMSO), [3-(4,5-Dimethylthiazol-2-yl)-2,5-Diphenyltetrazolium Bromide] (MTT), Dulbecco's Modified Eagle's Medium (DMEM), DMEM/F12 medium, fatal bovine serum (FBS), penicillin and streptomycin were purchased from Sigma (Beijing, China). Apoptosis assay kit, Reactive oxygen species kit, JC-1, and Antibodies specific to p-p38 MAPK, Bax, Bcl-2, cytochrome c, and caspase- 3 were purchased from Beyotime institute of Technology (Shanghai, China). Antibodies specific to $\beta$-actin and horseradish peroxidase-conjugated secondary antibodies (goat-anti-rabbit, goat-anti-mouse) were purchased from Santa Cruz (Beijing, China).

\section{Cell Culture and Treatments}

The human pancreatic carcinoma PANC-1, BxPC3, HPAC cells and monkey non-tumorigenic COS-7 cells were obtained from Shanghai Cell Bank. PANC-1, BxPC3 and COS-7 cells were cultured in Dulbecco's Modified Eagle's Medium (DMEM) supplemented with $10 \%$ fatal bovine serum (FBS), 100 units $/ \mathrm{mL}$ penicillin and $100 \mu \mathrm{g} / \mathrm{mL}$ streptomycin whereas HPAC cells were cultured in DMEM/F12 medium supplemented with $10 \%$ (FBS), 100 units/mL penicillin and $100 \mu \mathrm{g} / \mathrm{mL}$ streptomycin and maintained at $37^{\circ} \mathrm{C}$ with $5 \% \quad \mathrm{CO}_{2}$ in humidified atmosphere. Cells were treated with various concentrations of isoalantolactone dissolved in DMSO with a final DMSO concentration of $1 \%$ for $24 \mathrm{~h}$. DMSO treated cells were used as control.

\section{Determination of Cell Viability}

Cell viability was assessed by MTT assay as described previously [13]. Briefly PANC-1, BxPC3, and HPAC cells were treated with dimethyl sulfoxide (DMSO) or isoalantolactone in the presence or absence of $3 \mathrm{mM} \mathrm{NAC}$ for $24 \mathrm{~h}$. Following treatment, the MTT reagent was added $(500 \mu \mathrm{g} / \mathrm{mL})$ and cells were further incubated at $37^{\circ} \mathrm{C}$ for $4 \mathrm{~h}$. Subsequently $150 \mu \mathrm{L}$ DMSO was added to dissolve farmazan crystals and absorbance was measured at $570 \mathrm{~nm}$ in a microplate reader (Thermo Scientific). The percentage of cell viability was calculated as follows:

$$
\begin{gathered}
\text { Cell viability }(\%)=\left(\mathrm{A} 570_{\text {sample }}-\mathrm{A} 570_{\text {blank }}\right) / \\
\left(\mathrm{A} 570_{\text {control }}-\mathrm{A} 570_{\text {blank }}\right) \times 100
\end{gathered}
$$
Prism 5.

The $\mathrm{IC}_{50}$ Values were calculated using GraphPad 


\section{Live/Dead assay}

Live and dead cells were quantified using the fluorescent probes calcein acetoxymethylester (calcein $\mathrm{AM}$ ) and propidium iodide (PI). Celcein AM is cell membrane permeable and stains only viable cells whereas PI is cell membrane impermeable and stains only dead cells. To determine the effect of isoalantolactone on cancer cells and normal cells, pancreatic carcinoma cells (PANC-1) and normal cells (COS-7) were treated with 20 and $40 \mu \mathrm{M}$ isoalantolactone in the presence or absence of NAC for $24 \mathrm{~h}$. Subsequently, treated and untreated cells were collected, washed with phosphate buffered saline (PBS) and incubated with PBS solution containing $2 \mu \mathrm{M}$ calcein $\mathrm{AM}$ and $4 \mu \mathrm{M}$ PI in the dark for $20 \mathrm{~min}$ at room temperature. After washing, cells were resuspended in PBS and analyzed for the fluorescence of calcein and PI by flow cytometry (Beckman Coulter, Epics XL).

\section{Apoptosis assay by Annexin V-FITC and pro- pidium iodide (PI) staining}

PANC-1 cells were treated with isoalantolactone in a dose- and time-dependent manner in the presence or absence of $3 \mathrm{mM} \mathrm{NAC}$. After treatment, cells were harvested, washed with PBS, and resuspended in 200 $\mu \mathrm{L}$ of binding buffer containing $5 \mu \mathrm{L}$ Annexin $\mathrm{V}$ and put in the dark for $10 \mathrm{~min}$ according to the kit instructions (Beyotime, Shanghai, China). After incubation, cells were labeled with $10 \mu \mathrm{L}$ PI and samples were immediately analyzed by flow cytometry (Beckman Coulter, Epics XL).

\section{Hoechst 33258 staining for Nuclei Condensa- tion and Fragmentation}

PANC-1 cells were treated with $40 \mu \mathrm{M}$ isoalantolactone for various time points $(0,4,12$, and $24 \mathrm{~h})$. The cells were fixed with $4 \%$ paraformaldehyde for 30 min at room temperature. After washing with PBS, cells were stained with Hoechst $33258(50 \mu \mathrm{g} / \mathrm{mL})$ at $37^{\circ} \mathrm{C}$ for $20 \mathrm{~min}$ in the dark. At the end, the cells were washed and resuspended in PBS for the observation of nuclear morphology under fluorescence microscope (Olympus 1x71).

\section{Cell cycle analysis}

PANC-1 cells were treated with 20 and $40 \mu \mathrm{M}$ isoalantolactone for $24 \mathrm{~h}$. After treatment, cells were harvested, washed with PBS and fixed with $70 \%$ ethanol at $4^{\circ} \mathrm{C}$ for overnight. After washing twice with PBS, cells were stained with a solution containing 50 $\mu \mathrm{g} / \mathrm{mL}$ PI and $100 \mu \mathrm{g} / \mathrm{mL}$ RNase A for $30 \mathrm{~min}$ in the dark at room temperature. The DNA contents for cell cycle phase distribution were analyzed by flow cy- tometry (Beckman Coulter, Epics XL) using Cell Quest software.

\section{Measurement of Reactive Oxygen Species (ROS)}

The intracellular changes in ROS generation were measured by staining the cells with $2^{\prime}, 7^{\prime}$-dichlorofluorescein-diacetate (DCFH-DA) as described previously [13]. The fluorescent dye DCFH-DA is a cell membrane permeable and is converted into cell membrane impermeable nonfluorescent compound DCFH by intracellular esterases. Oxidation of DCFH by reactive oxygen species produces a highly fluorescent DCF. The fluorescence intensity of DCF inside the cells is proportional to the amount of peroxide produced. Briefly PANC-1 cells were treated with 20 and $40 \mu \mathrm{M}$ isolantolactone for $24 \mathrm{~h}$. After treatment, cells were further incubated with 10 $\mu \mathrm{M}$ DCFH-DA at $37^{\circ} \mathrm{C}$ for $30 \mathrm{~min}$. Subsequently, cells were harvested, rinsed, re-suspended in PBS, filtered with 300 apertures and analyzed for 2', 7' -dichlorofluorescein (DCF) fluorescence by flow cytometry.

\section{Measurement of Mitochondrial Membrane Lipid Peroxidation}

Mitochondrial membrane lipid peroxidation was determined by measuring the oxidation of intracellular cardiolipin by staining the cells with $10-\mathrm{N}$-nonyl acridine orange (NAO), a probe specific for mitochondrial membrane cardiolipin [14]. Briefly PANC-1 cells were treated with 20 and $40 \mu \mathrm{M}$ isoalantolactone for $24 \mathrm{~h}$. After washing with PBS, cells were further incubated with $5 \mu \mathrm{M}$ NAO in the dark at room temperature for $30 \mathrm{~min}$. After washing, samples were analyzed by flow cytometry.

\section{Measurement of Mitochondrial Membrane Potential (MMP)}

MMP was determined using JC-1 probe (Beyotime) as described previously [15, 16]. JC-1 is widely used to monitor mitochondrial membrane depolarization. In healthy cells with high mitochondrial membrane potential, JC-1 spontaneously forms complexes known as J-aggregates with intense red fluorescence. Whereas, in apoptotic or unhealthy cells with low mitochondrial membrane potential, JC-1 remains in the monomeric form, which shows only green fluorescence. Thus mitochondrial depolarization is indicated by a decrease in red/green fluorescence intensity ratio. Briefly after treating the cells with 20 and $40 \mu \mathrm{M}$ isoalantolactone for $24 \mathrm{~h}$, cells were stained with $10 \mu \mathrm{M}$ of $\mathrm{JC}-1$ for $25 \mathrm{~min}$ at $37^{\circ} \mathrm{C}$. After 
washing, cells were analyzed for the decrease in red/green fluorescence by flow cytometry.

\section{Immunobloting}

Proteins were isolated from control and isoalantolactone-treated cells as described previously [13]. $40 \mu \mathrm{g}$ proteins were electrophoresed on $10 \%$ SDS-PAGE and transferred to PVDF membrane. After blocking with $5 \%(\mathrm{w} / \mathrm{v})$ non-fat milk and washing with Tris-buffered saline-Tween solution (TBST), membranes were incubated overnight at $4^{\circ} \mathrm{C}$ with p-p38 MAPK (1:1000), Bcl-2 (1:1000), Bax (1:300), cytochrome c (1:200), caspase-3 (1:500) and $\beta$-actin (1:400) antibodies respectively. After washing, the blots were incubated with horseradish peroxidase-conjugated goat anti-rabbit IgG or goat anti-mouse IgG secondary antibodies (1:5000) for $1 \mathrm{~h}$ at room temperature. After washing with TBST, signals were detected using ECL plus chemiluminescence kit on X-ray film (Millipore Corporation). All the bands obtained were quantified by densitometry using Image J software.

\section{In Vivo Studies}

In vivo studies for acute and chronic toxicity were conducted on 10-12 week old CD1 mice weighing $27-30 \mathrm{~g}$. The mice were maintained in a specific pathogen-free grade animal facility on a 12-h light/dark cycles at $25 \pm 2^{\circ} \mathrm{C}$. Mouse procedures were approved by the Experimental Animal Committee of Jilin University. Mice were randomly divided into four groups. Group A (n=4) administered with $50 \mu \mathrm{L}$ DMSO intraperitonially for 7 days; Group B $(n=4)$ administered with isoalantolactone $(100 \mathrm{mg} / \mathrm{kg}$ body weight) in $50 \mu \mathrm{L}$ DMSO intraperitonially for 7 days; Group C ( $\mathrm{n}=4)$ administered with $50 \mu \mathrm{L}$ DMSO for 30 days and Group D $(n=4)$ administered with isoalantolactone $(100 \mathrm{mg} / \mathrm{kg}$ body weight) in $50 \mu \mathrm{L}$ DMSO intraperitonially for 30 days.

At the first and last day of the experiments, the body weight of each mouse was measured. At the end of experiments (at dose day 7 for acute toxicity \& dose day 30 for chronic toxicity), mice were anesthetized using Pentobarbital sodium (50 mg/ kg ip), blood was collected via cardiac puncture, allowed to clot for 10 $\mathrm{min}$ and centrifuge at $1000 \times \mathrm{g}$ for $10 \mathrm{~min}$ at room temperature. Serum was separated and stored at $-20^{\circ} \mathrm{C}$ until analysis. The liver and kidneys were excised and processed for hematoxylin and eosin staining followed established procedures.

\section{Serum Biomarker Analysis}

The acute and chronic toxicity of isoalantolactone on liver and kidneys was determined by meas- uring the serum levels of aspartate aminotransferase (AST), alanine aminotransferase (ALT), total bilirubin (TBIL), blood urea nitrogen (BUN) and creatinine (Cr) using blood auto analyzer (Hitechi 7170).

\section{Statistical Analysis}

The results are expressed as Mean \pm SEM and statistically compared with control group or within the groups using one way ANOVA followed by Tukey's Multiple Comparison Test. Student's T-test was used to determine significance when only two groups were compared and $\mathrm{p}<0.05$ was considered statistically significant.

\section{Results}

\section{Isoalantolactone Inhibibited Pancreatic Can- cer Cells Growth in Vitro.}

The cytotoxic effect of isoalantolactone on pancreatic carcinoma was evaluated using PANC-1, BxPC3 and HPAC cell lines. Treatment with isoalantolactone for $24 \mathrm{~h}$ inhibited PANC-1 cell growth in a dose-dependent manner (Fig 1A). The inhibition rate was above $90 \%$ at $80 \mu \mathrm{M}$ and the concentration to achieve $50 \%$ growth inhibition $\left(\mathrm{IC}_{50}\right)$ was $40 \mu \mathrm{M}$. A similar trend in loss of cell viability was observed in BxPC3 and HPAC cells on isoalantolactone treatment with $\mathrm{IC}_{50}$ values 43 and $48 \mu \mathrm{M}$ respectively (Fig. $1 \mathrm{~B} \&$ C). Pretreatment with $3 \mathrm{mM} \mathrm{NAC}$, a specific ROS scavenger, restored the viability of cells indicating that isoalantolactone exerts cytotoxic effect on cell viability through ROS generation. PANC-1 cell line was found more sensitive to isoalantolactone and selected for further mechanistic study.

\section{Cancer Cells are more sensitive to Isoalanto- lactone than Normal cells}

The cytotoxic effect of isoalantolactone on PANC-1 cells was further confirmed by live/dead assay. Apart from cancer cells, the cytotoxic effect of isoalantolactone on normal cells (COS-7 cells) was also evaluated. For this purpose, pancreatic carcinoma cells (PANC-1) and normal cells (COS-7) were treated with 20 and $40 \mu \mathrm{M}$ isoalantolactone for $24 \mathrm{~h}$ and live and dead cells were quantified using fluorescent probes calcein AM/PI and flow cytometry. The data showed that treatment of cells with isoalantolactone reduced the viability of PANC- 1 and COS-7 cells in a dose-dependent manner. However, the viability of COS-7 cells was significantly higher than PANC-1 cells after exposure to 20 and $40 \mu \mathrm{M}$ isoalantolactone for $24 \mathrm{~h}$ (Fig 2). Next, to examine whether ROS scavenger, NAC protects the cells from cytotoxic effect of isoalantolactone, PANC-1 and COS-7 cells were in- 
cubated with $40 \mu \mathrm{M}$ isoalantolactone in the presence of $3 \mathrm{mM} \mathrm{NAC}$ for $24 \mathrm{~h}$ and cell viability was determined by live/dead assay. The data demonstrated that NAC completely abolished isoalantolactone-induced cytotoxic effect in PANC-1 as well as in COS-7 cells. The data indicate that isoalantolactone-induced cytotoxicity in PANC-1 as well as in COS-7 cells is associated with generation of intracellular ROS. The differential toxicity of isoalantolactone between normal cells and cancer cells may be due to much lower level of endogenous ROS in normal cells than cancer cells.

\section{Isoalantolactone induces Apoptosis and S phase Arrest in PANC-I Cells}

Apoptosis and cell cycle arrest are two major causes of cell growth inhibition. The effect of isoalantolactone on cell apoptosis was analyzed by Annexin V-FITC/PI staining using flow cytometry and Hoechst 33258 staining using fluorescence microscope. The results showed that isoalantolactone induced apoptosis in PANC-1 cells in a dose- and time-dependent manner. Treatment of cells with 20 and $40 \mu \mathrm{M}$ isoalantolactone significantly increased apoptosis rate $(62.67 \pm 2.82$ and $69 \pm 4.23$ vs $2.88 \pm 0.59$ in control, P<0.01) (Fig. 3A). Pretreatment with NAC completely blocked the apoptotic effect of isoalantolactone indicating that induction of apoptosis is ROS-dependent. Next, we treated the cells with $40 \mu \mathrm{M}$ isoalantolactone and level of ROS and apoptosis rates were observed at different time points. The data demonstrated that isoalantolactone induced apoptosis (Fig. 3B) and ROS generation (Data not shown) in PANC-1 cells in a time-dependent manner. The isoalantolactone-induced apoptosis was also identified using Hoechst 33258 staining and fluorescence microscope at different time points. In the control group, the nuclei were round and stained homogeneously whereas isoalantolactone-treated cells showed condensed and marked fragmented nuclei in a time-dependent manner (Fig. 4). Taken together, the data demonstrate that isoalantolactone induces apoptosis in PANC-1 cells in a dose- and time-dependent manner which is correlated with ROS generation.

(A)
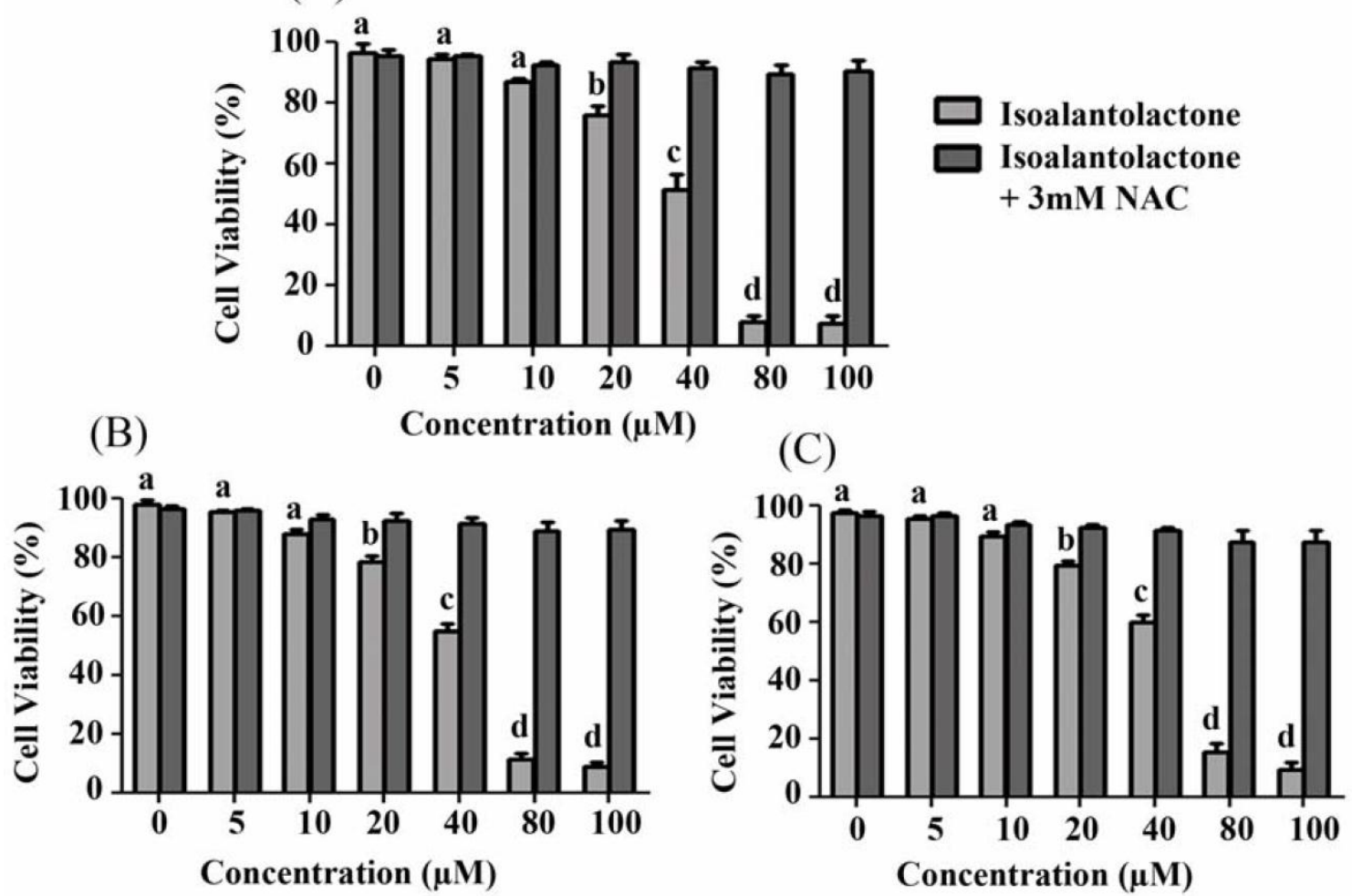

Figure I. Effect of isoalantolactone on PANC-I, BxPC3 and HAPC cells viability. Cells were treated with different concentrations of isoalantolactone in the presence or absence of NAC for $24 \mathrm{~h}$ and cell viability was measured by MTT assay. (A) PANC-I cells were treated with various concentrations of isoalantolactone for $24 \mathrm{~h}$. (B) BxPC3 cells were treated with various concentrations of isoalantolactone for $24 \mathrm{~h}$. (C) HPAC cells were treated with various concentrations of isoalantolactone for $24 \mathrm{~h}$. Data are expressed as Mean \pm SEM ( $\mathrm{n}=3$ ). Columns not sharing the same superscript letter differ significantly $(P<0.05)$. 

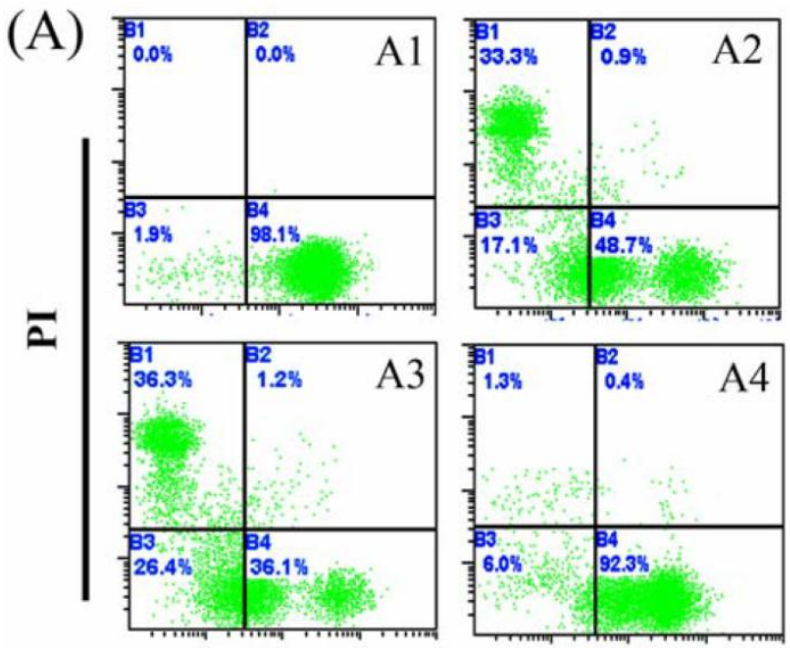

(B)
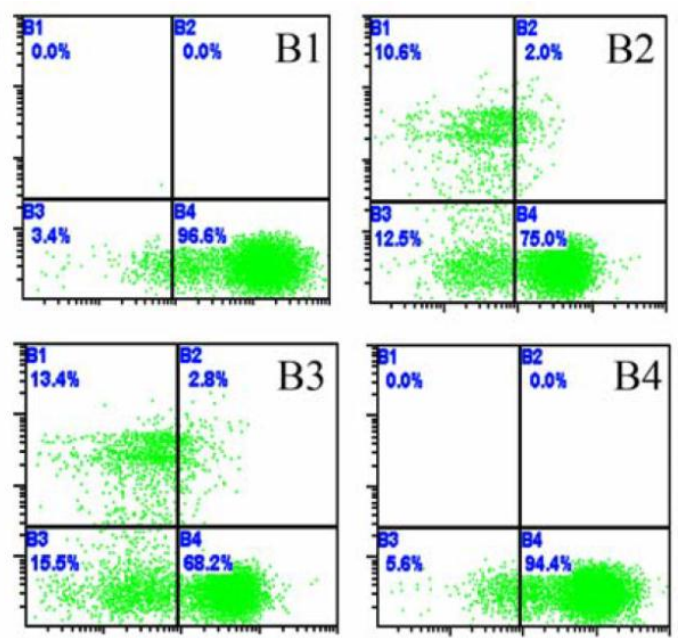

\section{Calcein}

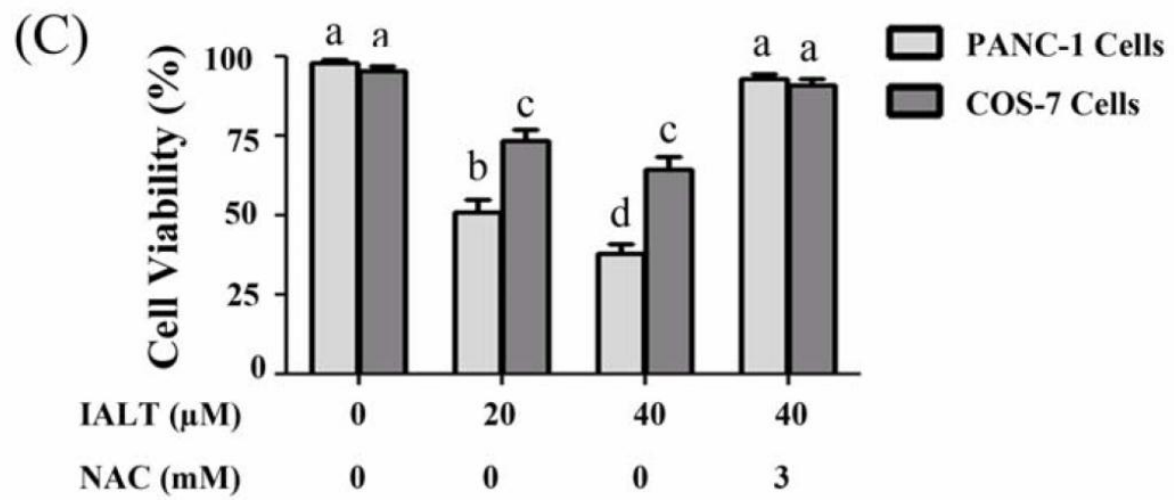

Figure 2. Determination of cell viability by Calcein/PI staining and Flow Cytometry (A) PANC-I cells were treated with 20 and $40 \mu M$ isoalantolactone in the presence or absence of NAC for $24 \mathrm{~h}$. (AI) Control, (A2) $20 \mu \mathrm{M}$, (A3) $40 \mu \mathrm{M}$, (A4) $40 \mu \mathrm{M}$ isoalantolactone $+3 \mathrm{mM}$ NAC. (B) COS-7 cells were treated with 20 and $40 \mu \mathrm{M}$ isoalantolactone in the presence or absence of NAC for $24 \mathrm{~h}$. (BI) Control, (B2) $20 \mu \mathrm{M}$, (B3) $40 \mu \mathrm{M}$, (B4) $40 \mu \mathrm{M}$ isoalantolactone $+3 \mathrm{mM}$ NAC. (C) Data are expressed as Mean $\pm \mathrm{SEM}(\mathrm{n}=3$ ). Columns not sharing the same superscript letter differ significantly $(P<0.05)$.

Induction of cell cycle arrest was analyzed using PI staining and flow cytometry. Our results showed that isoalantolactone arrested the cell cycle at $\mathrm{S}$ phase in a dose-dependent manner. Treatment with isoalantolactone at 20 and $40 \mu \mathrm{M}$ showed a significant increase in $S$ phase from $19.73 \pm 1.94$ to $31 \pm 1.53$ \& $49.23 \pm 1.43$ with a corresponding decrease in G0/G1 phase from $59.48 \pm 3.43$ to $56.13 \pm 1.82 \& 47.36 \pm 0.91$ and G2/M phase from $22.5 \pm 1.21$ to $13.16 \pm 0.78 \& 3.26 \pm 0.69$ respectively at $\mathrm{P}<0.05$ (Fig. 5).

\section{Isoalantolactone induces Increased Genera- tion of ROS in PANC-I Cells}

Intracellular ROS generation in PANC-1 cells was evaluated by flow cytometry using DCFH-DA. As shown in Fig. 6A, the level of ROS in PANC-1 cells, treated with 20 and $40 \mu \mathrm{M}$ isoalantolactone was significantly higher $(21.33 \pm 1.45 \& 33.0 \pm 1.73$ vs $1.02 \pm 0.47$ in control group, $\mathrm{P}<0.05)$.

\section{Isoalantolactone causes Cardiolipin Oxidation (CL oxidation) and Disrupt Mitochondrial Membrane Potential (MMP) in PANC-I Cells}

Reactive oxygen species once generated cause massive oxidation of redox sensitive proteins and lipids leading to mitochondrial damage. Next we asked if isoalantolactone can cause mitochondrial cardiolipin (CL) oxidation. Cardiolipin is exclusively found in mitochondria and cytochrome $\mathrm{c}$ is bound to cardiolipin. Oxidation of cardiolipin results in liberation of cytochrome $\mathrm{c}$ from mitochondrial membrane. To examine CL oxidation, cells were stained with $\mathrm{NAO}$, and CL oxidation was determined by flow cytometry. The data showed that isoalantolactone caused CL oxidation in PANC-1 cells in a dose-dependent manner (Fig. 6B). 

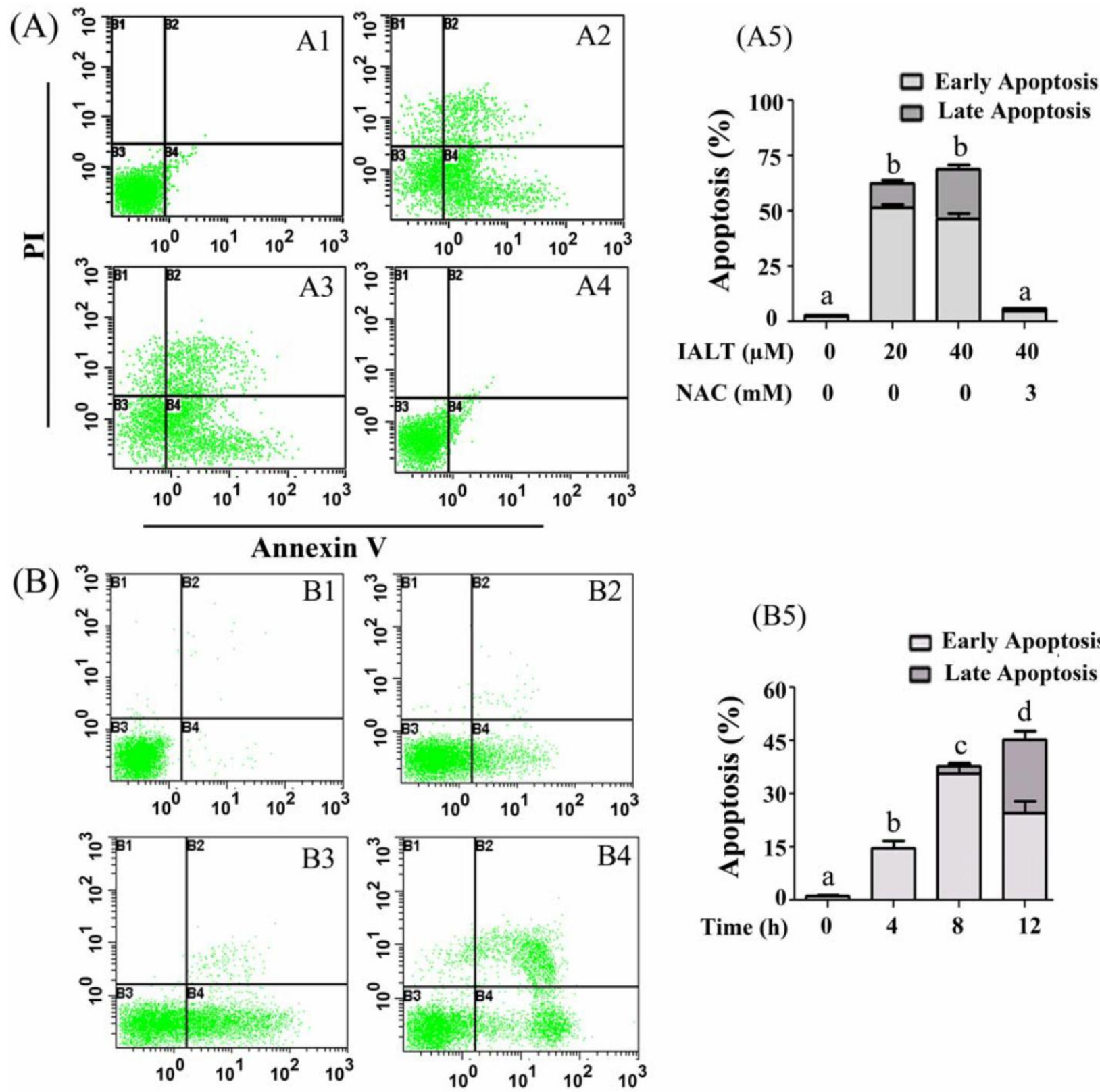

Figure 3. Flow cytometry analysis of apoptosis in PANC-I cells treated with isoalantolactone in a dose- and time-dependent manner in the presence or absence of $3 \mathrm{mMNAC}$. (A) PANC-I cells were treated with 20 and $40 \mu \mathrm{M}$ isoalantolactone in the presence or absence of NAC for 24 h. (AI) Control, (A2) $20 \mu \mathrm{M}$, (A3) $40 \mu \mathrm{M}$, (A4) $40 \mu \mathrm{M}$ isoalantolactone $+3 \mathrm{mM}$ NAC, (A5) Data are expressed as Mean $\pm \operatorname{SEM}(n=3)$. Columns not sharing the same superscript letter differ significantly $(P<0.05)$. (B) PANC-I cells were treated with $40 \mu M$ isoalantolactone for various time intervals. (BI) Control, (B2, B3 and B4) PANC-I cells were treated with $40 \mu M$ isoalantolactone for 4 , 8 and 12 h respectively. (B5) Data are expressed as Mean \pm SEM $(n=3)$. Columns not sharing the same superscript letter differ significantly $(\mathrm{P}<0.05)$. 
Figure 4. Induction of apoptosis by isoalantolactone in PANC-I cells using Hoechst 33258 staining and fluorescence microscope. PANC-I cells were treated with $40 \mu \mathrm{M}$ isoalantolactone for various time intervals and nuclear morphological changes were observed using Hoechst 33258 staining and fluorescence microscope. The cells treated with $40 \mu \mathrm{M}$ isoalantolactone for various time intervals exhibited apoptotic changes such as condensed chromatin and fragmented nuclei as indicated by arrows. (A) Control, (B, C, and D) Cells were treated with $40 \mu \mathrm{M}$ isoalantolactone for 4,12 and $24 \mathrm{~h}$ respectively. Cell were fixed with $4 \%$ paraformaldehyde, washed with PBS, resuspended in PBS and observed under fluorescence microscope for nuclear morphological changes. Scale bar $=20 \mu \mathrm{m}$.
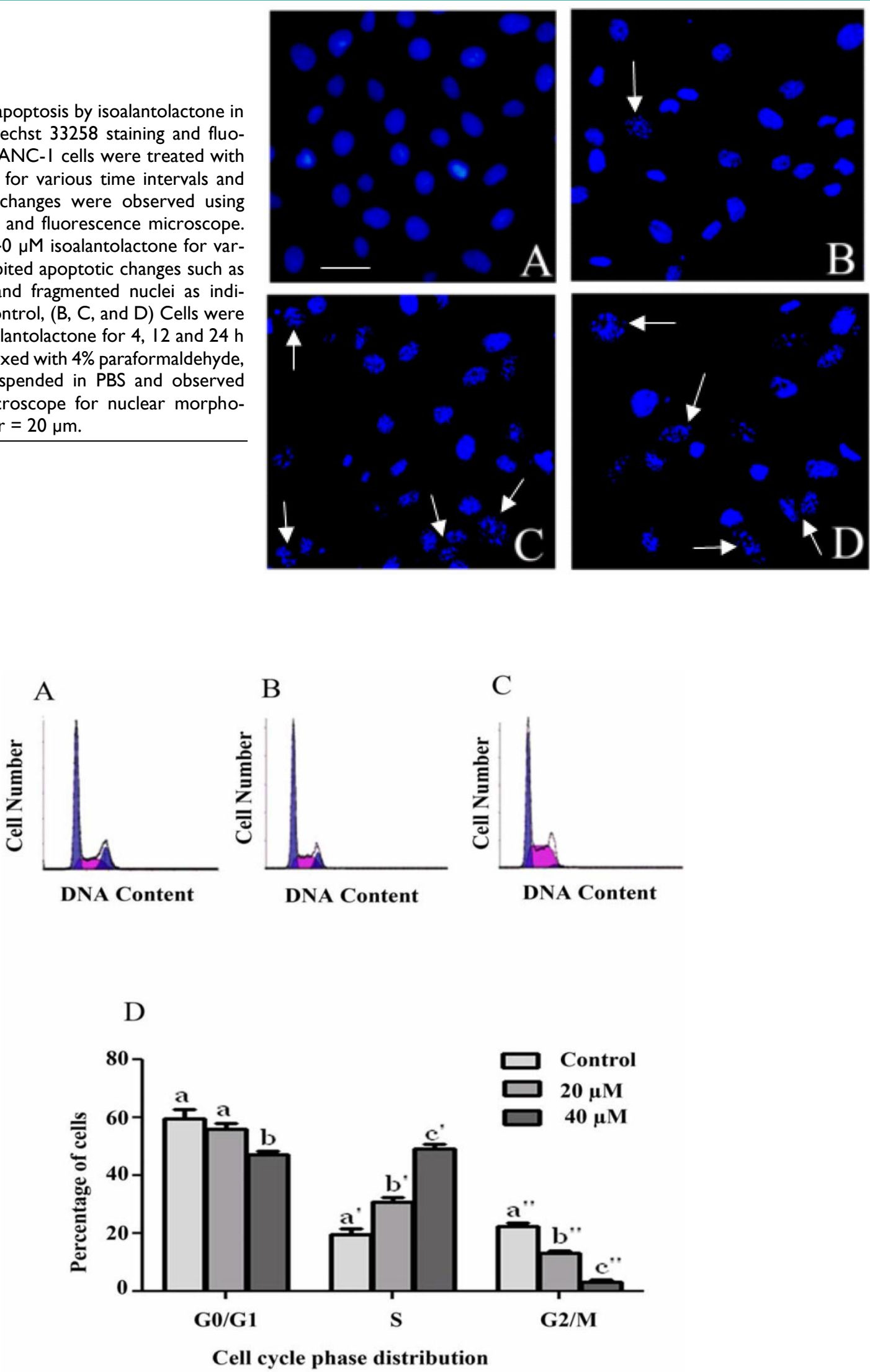

Figure 5. Flow cytometry analysis of cell cycle phase distribution in PANC-I cells treated with 20 and $40 \mu \mathrm{M}$ isoalantolactone for $24 \mathrm{~h}$. (A) Control, (B) $20 \mu M$, (C) $40 \mu$ M. (D) Data are expressed as Mean \pm SEM ( $n=3)$. Columns not sharing the same superscript letter differ significantly $(P<0.05)$ 
(A)
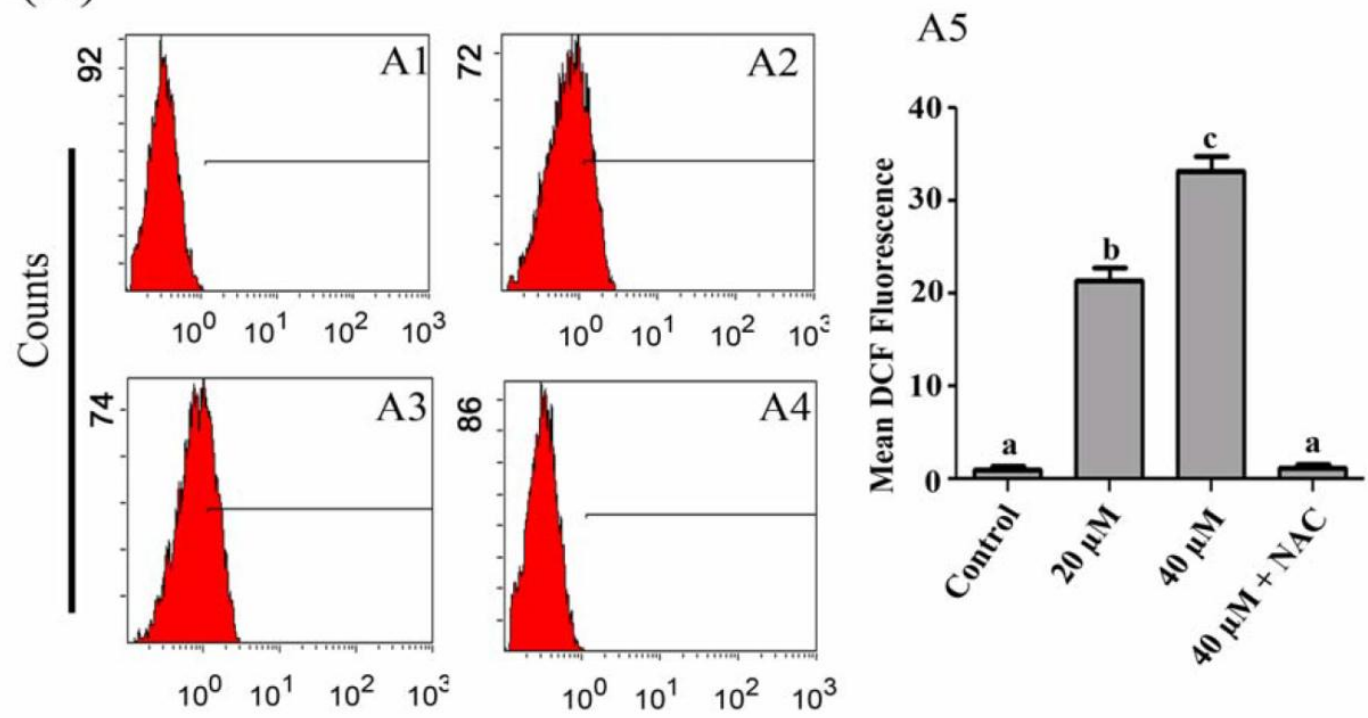

Fluorescence intensity

(B)
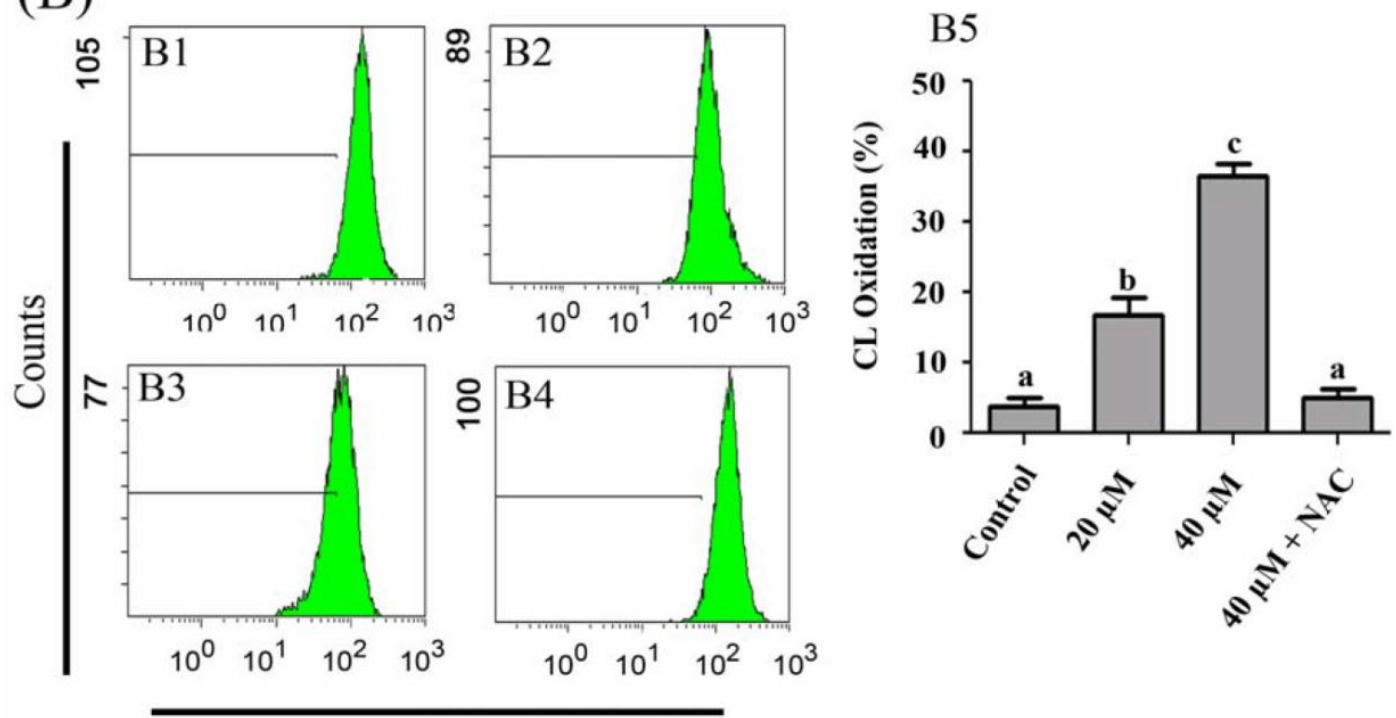

Fluorescence intensity

Figure 6. Flow cytometry analysis of ROS generation (A) and Cardiolipin oxidation (B) in PANC-I cells treated with 20 and $40 \mu M$ IALT in the presence or absence of $3 \mathrm{mM} \mathrm{NAC}$ for $24 \mathrm{~h}$. (Al) Control, (A2) $20 \mu \mathrm{M}$, (A3) $40 \mu \mathrm{M}$, (A4) $40 \mu \mathrm{M}$ isoalantolactone + $3 \mathrm{mM}$ NAC, (A5) Data are expressed as Mean \pm SEM $(n=3)$. Columns not sharing the same superscript letter differ significantly $(P<0.05)$. $(B I) C o n t r o l$, (B2) $20 \mu \mathrm{M}$, (B3) $40 \mu \mathrm{M}$, (B4) $40 \mu \mathrm{M}$ isoalantolactone $+3 \mathrm{mM}$ NAC, (B5) Data are expressed as Mean \pm SEM ( $n=3$ ). Columns not sharing the same superscript letter differ significantly $(P<0.05)$

Depolarization in MMP is a characteristic feature of apoptosis. Excessive intracellular ROS production has been shown to induce apoptosis by disrupting MMP $[16,17]$. To investigate the role of ROS in isoalantolactone-mediated apoptosis, we determined MMP in PANC-1 cells using JC-1 and flow cytometry.
As shown in Fig. 7, MMP in cells treated with 20 and $40 \mu \mathrm{M}$ isoalantolactone was significantly lower $(89.43 \pm 1.75 \%$ \& $84.40 \pm 0.92 \%$ vs $98.03 \pm 0.55 \%$ in control group, $\mathrm{P}<0.05)$. To further confirm the involvement of ROS in CL oxidation and disruption of MMP, cells were treated with $3 \mathrm{mM}$ NAC. Pretreatment with 
NAC completely prevented CL oxidation and drop in MMP, indicating that both these processes are ROS-dependent.

\section{Effect of Isoalantolactone on Major Mito- chondrial Apoptosis Regulatory Proteins}

To further characterize mitochondrial apoptosis in detail, the effect of isoalantolactone on the expression of some major proteins (p38 MAPK, Bax, Bcl-2, cytochrome $c$ and caspase-3) involved in mitochondrial apoptosis pathway was determined by Western blot analysis. Previous studies have shown that in- creased intracellular ROS generation can activate p38 MAP kinase [18] and activated p38 MAPK plays important role in activation and translocation of Bax which ultimately results in release of cytochrome $c$ and activation of caspase- $3[19,20]$. To observe whether p38 MAP kinase is activated by isoalantolactone, we checked the expression of p38 MAPK using a phosphospecific antibody recognizing active p38 MAPK by Western blot analysis. The results showed an increased expression of phosphorylated p38 MAPK in isoalantolactone-treated cells (Fig. 8A).

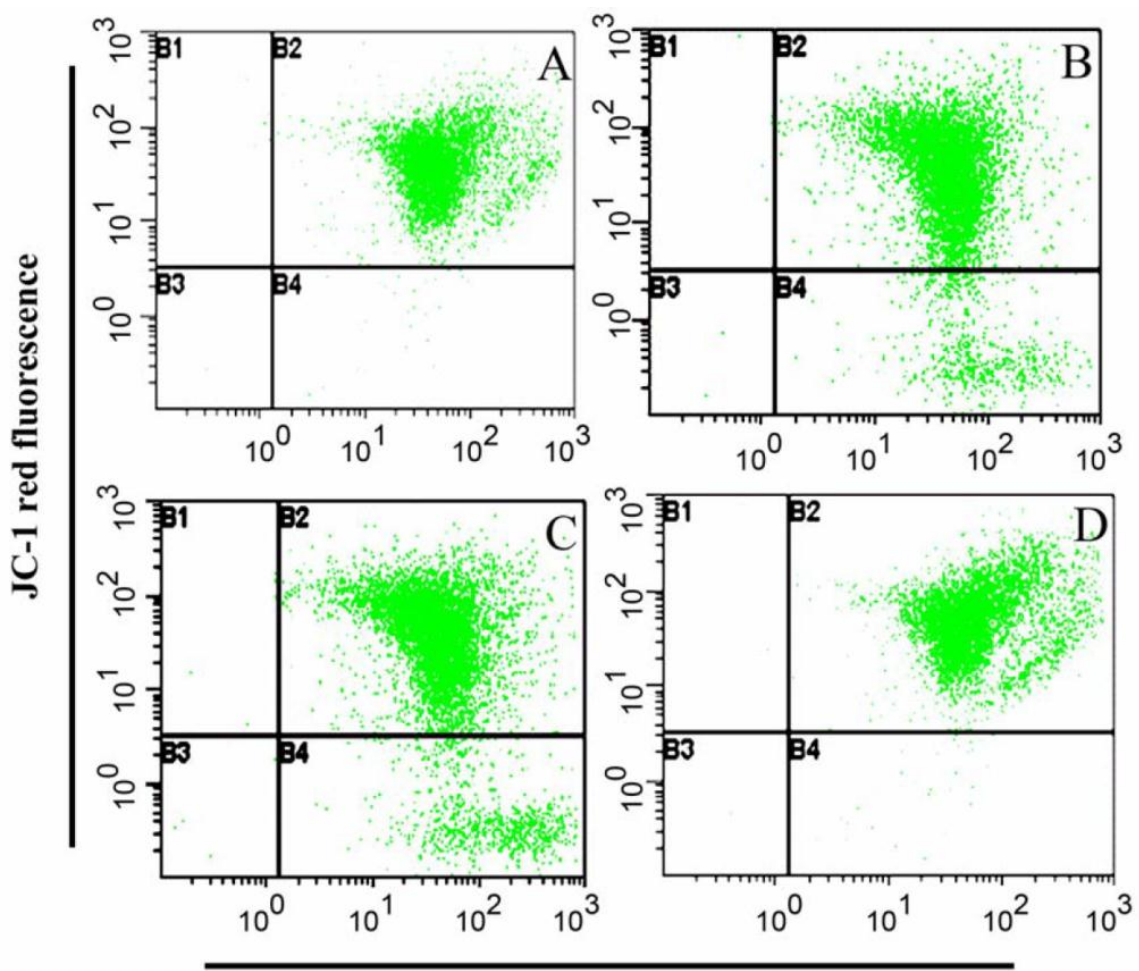

JC-1 green fluorescence

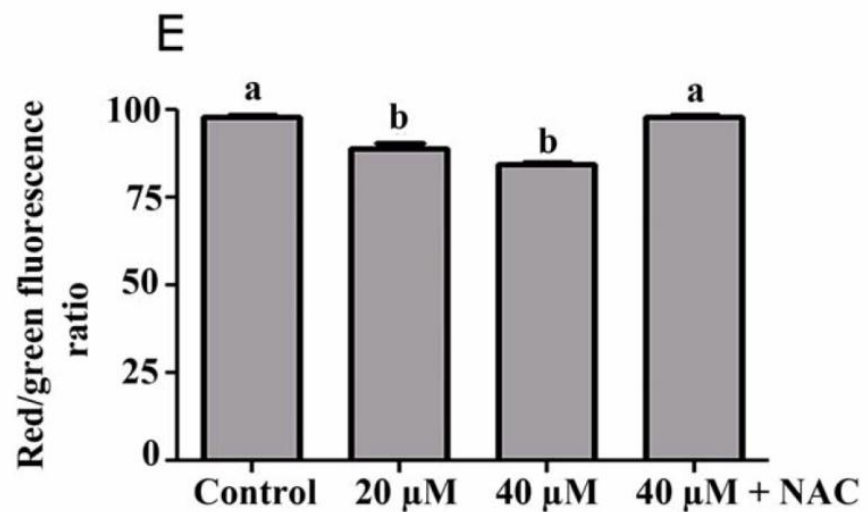

Figure 7. Flow cytometry analysis of mitochondrial membrane potential in PANC-I cells treated with 20 and $40 \mu M$ isoalantolactone in the presence or absence of $3 \mathrm{mM}$ NAC for $24 \mathrm{~h}$. (A) Control, (B) $20 \mu \mathrm{M}$, (C) $40 \mu \mathrm{M}$, (D) $40 \mu \mathrm{MIALT}+3 \mathrm{mM}$ NAC, (E) Data are expressed as Mean $\pm \operatorname{SEM}(n=3)$. Columns not sharing the same superscript letter differ significantly $(P<0.05)$. 


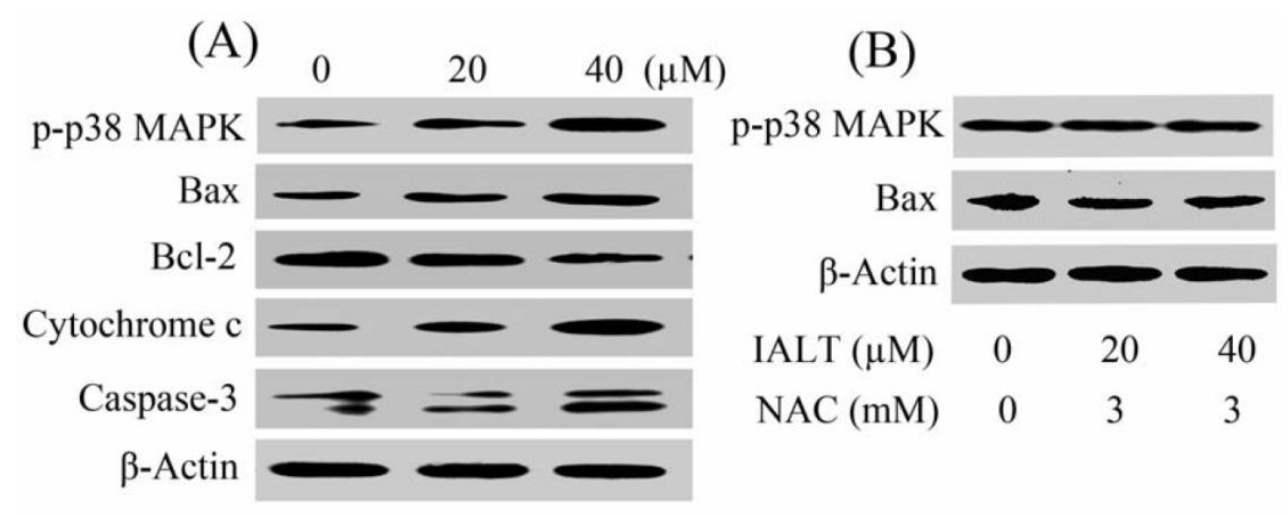

(C)

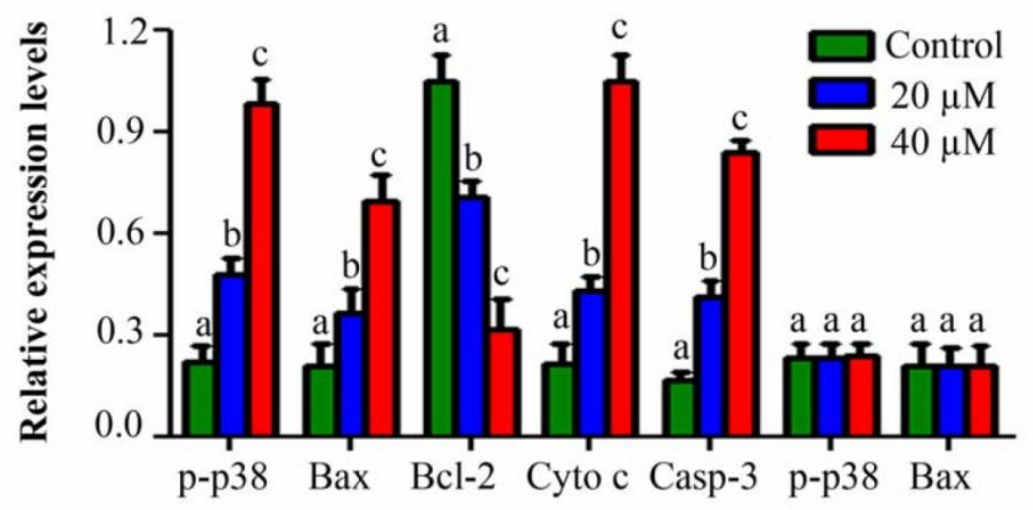

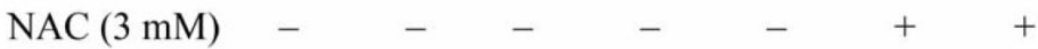

Figure 8. Effect of isoalantolactone on the expression of major apoptosis regulatory proteins (A) PANC-I cells were treated with 20 and $40 \mu \mathrm{M}$ isoalantolactone for 24 . The expressions of $\mathrm{p}-\mathrm{p} 38, \mathrm{Bcl}-2$, Bax, cytochrome $\mathrm{c}$ and caspase-3 were determined by Western blotting and quantified by Image J software. (B) PANC-I cells were treated with 20 and $40 \mu$ isoalantolactone in the presence of 3 mM NAC for $24 \mathrm{~h}$. The expressions of p-p38 and Bax were determined by Western blot analysis and quantified by Image J software. (C) Data are expressed as Mean \pm SEM $(n=3)$. Columns not sharing the same superscript letter within the group differ significantly $(P<0.05)$

To further investigate, we analyzed the expression of Bax, Bcl-2, cytochrome $\mathrm{c}$ and caspase-3 in PANC-1 cells after exposure to 20 and $40 \mu \mathrm{M}$ isoalantolactone for $24 \mathrm{~h}$. As shown in Fig. 8A, isoalantolactone treatment increased the expression of Bax and decreased the expression of Bcl-2 accompanied by the release of cytochrome $c$ from mitochondria to cytosol and caspase- 3 activation in a dose-dependent manner. To investigate whether increased ROS generation is functionally linked to isoalantolactone-induced p38 MAPK and Bax activation, we observed the expressions in the cell lysates treated with isoalantolactone in the presence of NAC. No change in the expression levels of p38 MAPK and Bax was observed, further confirming that activation of both these proteins is ROS-dependent (Fig. 8B).

\section{Isoalantolactone Exerts no Toxic Effect on Liver and Kidneys in Vivo}

The acute and chronic toxic effects of isoalanto- lactone in CD1 mice were assessed by measuring the changes in body weight, blood biochemistry and histopathology of liver and kidneys in comparison with control groups.

The drug was well tolerated by mice and no mortality or any sign of pharmacotoxicity were found at a dose of $100 \mathrm{mg} / \mathrm{kg}$ during both experimental periods (7 \& 30 days). Body weight gains and food consumption were comparable for control and treated mice during both experimental periods and there were no drug-related changes in histopathological and blood biochemistry parameters. The histopathological changes in liver and kidneys were assessed using hematoxylin and eosin staining and correlated with liver and renal function biomarkers. No obvious morphological changes were observed in liver and kidney structures of control and treatment groups (Fig 9). These results were further confirmed by measuring the changes in liver function biomarkers (AST, ALT and TBIL) and renal function biomarkers 
(BUN and $\mathrm{Cr}$ ) in the serum of control and treatment groups. As shown in Table 1, there was a slight increase in serum ALT and AST level of treatment group at dose day 7 but this increase was not significantly different $(\mathrm{P}<0.05)$ from control group. However, a significant increase in TBIL concentration was found in treatment group $(1.43 \pm 0.26$ vs $0.76 \pm 0.12$ in control, $\mathrm{P}<0.05$ ) at dose day 7 . Similarly the changes in renal function biomarkers (Cr \& BUN) were not sig- nificantly different $(\mathrm{P}<0.05)$ in the serum of control and treatment groups at dose day 7 . The concentration of $\mathrm{Cr}$ slightly increased whereas concentration of BUN slightly decreased in treatment group (Table 1). Interestingly, the serum level of AST, ALT, TBIL and BUN slightly decreased when mice were injected with isoalantolactone at a dose of $100 \mathrm{mg} / \mathrm{kg}$ for 30 days (Table 1). However, these alterations do not differ significantly from control group $(\mathrm{P}<0.05)$.

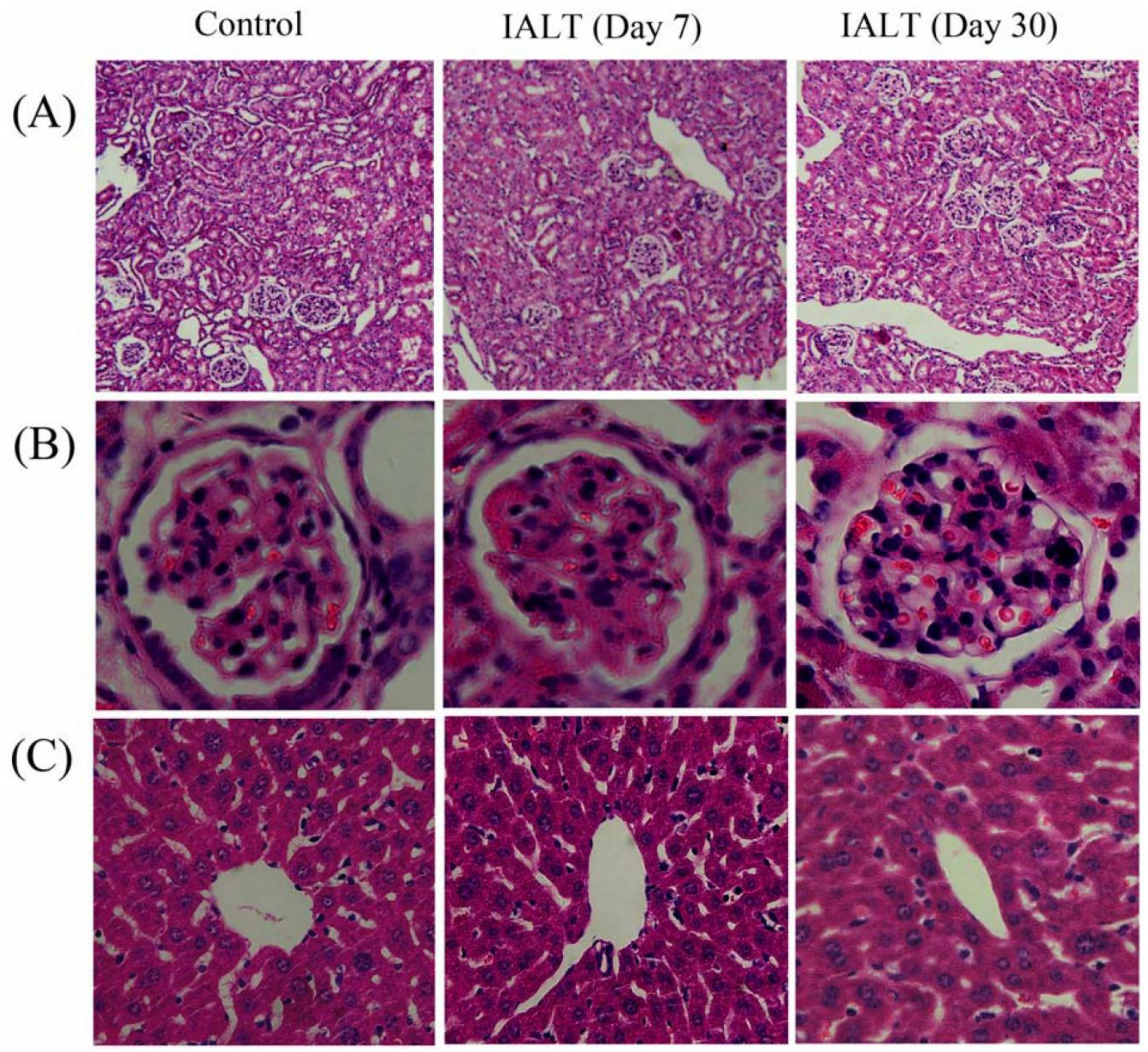

Figure 9. Hematoxylin \& Eosin stained sections of Kidney and Liver from CDI mice administered with vehicle or isoalantolactone at a dose of $100 \mathrm{mg} / \mathrm{kg}$ body weight. The liver and kidneys from control and IALT-treated mice were excised and processed for hematoxylin and eosin staining followed established procedures. (A) Kidney section; Scale bar $=100 \mu \mathrm{m}$. (B) kidneys sections representing structure of glomeruli; Scale bar $=20 \mu \mathrm{m}$. (C) Liver section; Scale bar $=20 \mu \mathrm{m}$. 
Table I: Biochemical effect of isoalantolactone on Liver and Kidneys function Biomarkers in CDI mice.

\begin{tabular}{|c|c|c|c|c|c|c|c|}
\hline \multirow[t]{2}{*}{ Groups } & \multicolumn{2}{|c|}{ Body Weight (g) } & \multirow{2}{*}{$\begin{array}{l}\text { ALT } \\
(\mathrm{U} / \mathrm{L})\end{array}$} & \multirow{2}{*}{$\begin{array}{l}\text { AST } \\
(\mathrm{U} / \mathrm{L})\end{array}$} & \multirow{2}{*}{$\begin{array}{l}\text { TBIL } \\
(\mu \mathrm{mol} / \mathrm{L})\end{array}$} & \multirow{2}{*}{$\begin{array}{l}\mathrm{Cr} \\
(\mu \mathrm{mol} / \mathrm{L})\end{array}$} & \multirow{2}{*}{$\begin{array}{l}\mathrm{BUN} \\
(\mathrm{mmol} / \mathrm{L})\end{array}$} \\
\hline & $\begin{array}{l}\text { Before } \\
\text { treatment }\end{array}$ & $\begin{array}{l}\text { After } \\
\text { treatment }\end{array}$ & & & & & \\
\hline Group A & $28.8 \pm 1.5$ & $30.4 \pm 1.3$ & $53.33 \pm 6.64$ & $156 \pm 5.50$ & $0.76 \pm 0.12$ & $19.46 \pm 2.79$ & $7.95 \pm 1.10$ \\
\hline Group B & $28.1 \pm 1.7$ & $26.9 \pm 1.8$ & $59.00 \pm 11.01$ & $158.7 \pm 10.17$ & $1.43 \pm 0.26^{\circ}$ & $28.03 \pm 7.53$ & $7.39 \pm 0.66$ \\
\hline Group C & $29.5 \pm 2.1$ & $33.8 \pm 2.2$ & $46.5 \pm 8.68$ & $143.25 \pm 5.94$ & $0.97 \pm 0.20$ & $20.27 \pm 2.68$ & $9.78 \pm 1.20$ \\
\hline Group D & $30.0 \pm 1.9$ & $33.7 \pm 1.6$ & $41.0 \pm 6.41$ & $137.50 \pm 12.2$ & $0.72 \pm 0.14$ & $20.62 \pm 5.34$ & $9.12 \pm 0.66$ \\
\hline
\end{tabular}

Data are expressed as Mean \pm SEM, $n=4$

* Significantly different from control, $p<0.05$

Group A \& B were daily given $50 \mu \mathrm{L}$ DMSO and isoalantolactone $(100 \mathrm{mg} / \mathrm{kg})$ for 7 days respectively.

Group C \& D were daily given $50 \mu \mathrm{L}$ DMSO and isoalantolactone $(100 \mathrm{mg} / \mathrm{kg})$ for 30 days respectively.

\section{Discussion}

Previous studies have indicated that root extract of Inula helenium has inhibitory activity against various cancer cell lines [21, 22]. One recent study by Pal et al. has shown that Inula recemosa extract containing alantolactone and isoalantolactone induces apoptosis and increased ROS generation in HL-60 cells [12]. However, the role of ROS remained undefined. In the present study, we addressed the question of whether or not isoalantolactone could induce apoptosis and increase ROS generation in PANC- 1 cells. To address the question, we examined the antiproliferative, apoptotic and ROS generating ability of isoalantolactone using MTT assay and flow cytometry. The results showed that isoalantolactone inhibited growth of PANC-1 cells and induced apoptosis and ROS generation in a dose-dependent manner. To probe the possible role of ROS, we performed MTT assay, Live/dead assay and apoptosis assay in the presence of a specific ROS inhibitor, NAC. The results showed that pretreatment with NAC restored cell viability and blocked the apoptotic effect of isoalantolactone completely. The data demonstrate clearly that isoalantolactone exerts its growth inhibitory effect through ROS generation. The present study provides evidence for the first time that isoalantolactone induces ROS-dependent apoptosis in PANC-1 cells.

Over production of ROS results in oxidative damage including; lipid peroxidation, protein oxidation and DNA damage. In addition, ROS are known to act as second messengers to activate diverse redox-sensitive signalling cascades including mitochondrial intrinsic apoptotic cascade through interaction with Bcl-2 family proteins, MAPK family member p38 and its downstream transcription factors [17, 23-25]. Bcl-2 family proteins include a wide variety of anti-apoptotic proteins such as $\mathrm{Bcl}-2$ and pro-apoptotic proteins such as Bax, which are key players of mitochondrial outer membrane permeabilization and apoptosis regulation $[26,27]$. ROS have been shown to inhibit anti-apoptotic protein Bcl-2 and activate and translocate pro-apoptotic protein Bax to outer mitochondrial membrane (OMM) where it forms oligomers, which are thought to be important in the formation of permeability transition pores (PTP) and cytochrome $c$ release. Some other studies have shown that ROS activate p38 MAPK [18] and activated $\mathrm{p} 38$ MAPK promotes the activation and translocation of Bax to OMM [25, 28].

In the present study, isoalantolactone increased ROS production in PANC-1 cells in a time- and dose-dependent manner. To investigate whether isoalantolactone can trigger intrinsic apoptotic cascade in PANC-1 cells, we examined the expression of Bcl-2, p38 MAPK and Bax proteins in the cells of each group using Western blot analysis. The results demonstrated that expression of $\mathrm{Bcl}-2$ gradually decreased while expression of p38 MAPK and Bax increased in cells of treatment groups in a dose-dependent manner, suggesting that isoalantolactone induces apoptosis through intrinsic pathway. In addition, massive CL oxidation, reduction in MMP and cytochrome $\mathrm{c}$ release into cytosol in isoalantolactone-treated cells further support the above findings. These results are consistent with previous study where n-hexane fraction of roots of Inula recemosa reduced the MMP with increase expression of Bax and cytochrome $\mathrm{c}$ release in HL-6o cells [12].

Once cytochrome $\mathrm{c}$ is released to cytosol, it binds and activates caspase-9, which then results in the activation of other downstream caspases and ultimately caspase-3. Caspase- 3 has been identified as a main executioner of apoptotic response inside the cells. Finally activated caspase- 3 cleaved effector proteins including PARP, and induced DNA fragmentation in nucleus which eventually leads to cell death [17]. In the present study, an increase in the cleaved caspase-3 
has been observed in isoalantolactone-treated cells. These results demonstrate clearly that isoalantolactone induces apoptosis in PANC-1 cells through mitochondrial dysfunction and caspase- 3 activation. It has been reported previously that increased intracellular ROS generation induces the cell cycle arrest at $S$ phase $[29,30]$. Our cell cycle analysis results clearly confirm these findings.

A number of previous studies have shown that the phytochemicals targeting ROS metabolism can selectively kill the cancer cells by raising the level of ROS above a toxic threshold $[7,8,31]$. As cancer cells contain higher level of basal endogenous ROS than normal cells [32], the toxic threshold value in cancer cells can be achieved faster compared to normal cells [33]. In the present study, isoalantolactone showed strong growth inhibitory effect towards PANC-1 cells; however this growth inhibitory effect of isoalantolactone towards normal cells (COS-7) was significantly lower compared to the cancer cells. In addition, isoalantolactone did not cause any dectectable acute or chronic toxicity in liver and kidneys of CD1 mice in vivo at a dose of $100 \mathrm{mg} / \mathrm{kg}$ body weight. This selective toxicity of isoalantolactone between cancer cells and normal cells may be due to much lower level of endogenous ROS in normal cells than cancer cells. However, a detailed investigation of this selective cytotoxicity of isoalantolactone still needs to be performed in vivo.

In conclusion, our data demonstrated for the first time that isoalantolactone induced ROS-dependent apoptosis in PANC-1 cells through mitochondrial intrinsic pathway. Furthermore, the different effect of isoalantolactone between cancer cells and normal cells might be dependent on different level of endogenous ROS. Our results suggest that isoalantolactone may be a promising chemotherapeutic drug candidate for the treatment of pancreatic carcinoma. Further investigation is needed to validate the contribution of isoalantolactone to tumor therapy in vivo.

\section{Acknowledgment}

This work is supported by Ministry of Education, Pakistan and Chinese Scholarship Council, China.

\section{Competing Interests}

The authors have declared that no competing interest exists.

\section{References}

1. Jemal A, Siegel R, Ward E, et al. Cancer statistics, 2009. CA Cancer J Clin. 2009; 59: 225-249
2. Yip-Schneider MT, Nakshatri H, Sweeney CJ, et al. Parthenolide and sulindac cooperate to mediate growth suppression and inhibit the nuclear factor-kappa B pathway in pancreatic carcinoma cells. Mol Cancer Ther. 2005; 4: 587-594

3. Awasthi N, Kirane A, Schwarz MA, et al. Smac mimetic-derived augmentation of chemotherapeutic response in experimental pancreatic cancer. BMC Cancer. 2011; 11: 15.

4. Arlt A, Gehrz A, Muerkoster S, et al. Role of NF-kappaB and $\mathrm{Akt} / \mathrm{PI} 3 \mathrm{~K}$ in the resistance of pancreatic carcinoma cell lines against gemcitabine-induced cell death. Oncogene. 2003; 22: 3243-3251.

5. Ou YQ, Zhu W, Li Y, et al. Aspirin inhibits proliferation of gemcitabine-resistant human pancreatic cancer cells and augments gemcitabine-induced cytotoxicity. Acta Pharmacol Sin. 2010; 31: 73-80.

6. El-Sayyad HI, Ismail MF, Shalaby FM, et al. Histopathological effects of cisplatin, doxorubicin and 5-flurouracil (5-FU) on the liver of male albino rats. Int J Biol Sci. 2009; 5: 466-473.

7. Schumacker PT. Reactive oxygen species in cancer cells: live by the sword, die by the sword. Cancer Cell. 2006; 10: 175-176.

8. Fruehauf JP, and Meyskens FLJr. Reactive oxygen species: a breath of life or death? Clin Cancer Res. 2007;13: 789-794.

9 Lyss G, Knorre A, Schmidt TJ, et al. The anti-inflammatory sesquiterpene lactone helenalin inhibits the transcription factor NF-kappaB by directly targeting p65. J Biol Chem. 1998; 273: 33508-16.

10 Ghantous A, Gali-Muhtasib H, Vuorela H, et al. What made sesquiterpene lactones reach cancer clinical trials? Drug Discov Today. 2010; 15: 668-78.

11 Zhang S, Won YK, Ong CN, et al. Anti-cancer potential of sesquiterpene lactones: bioactivity and molecular mechanisms. Curr Med Chem Anticancer Agents. 2005; 5: 239-49.

12. Pal HC, Sehar I, Bhushan S, et al. Activation of caspases and poly (ADP-ribose) polymerase cleavage to induce apoptosis in leukemia HL-60 cells by Inula racemosa. Toxicol In Vitro. 2010; 24: 1599-1609.

13. Khan M, Yu B, Rasul A, et al. Jaceosidin induces apoptosis in U87 glioblastoma cells through G2/M phase arrest. Evid-based comp Alt Med; doi:10.1155/2012/703034

14. Trachootham D, Zhou $\mathrm{Y}$, Zhang $\mathrm{H}$, et al. Selective killing of oncogenically transformed cells through a ROS-mediated mechanism by beta-phenylethyl isothiocyanate. Cancer Cell. 2006; 10: 241-252.

15. Lv W, Sheng $X$, Chen T, et al. Jaceosidin induces apoptosis in human ovary cancer cells through mitochondrial pathway. J Biomed Biotechnol. 2008; 2008: 394802.

16. Ling X, Zhou Y, Li SW, et al. Modulation of mitochondrial permeability transition pore affects multidrug resistance in human hepatocellular carcinoma cells. Int J Biol Sci.2010; 6: 773-783.

17. Ji YB, Qu ZY, and Zou X. Juglone-induced apoptosis in human gastric cancer SGC-7901 cells via the mitochondrial pathway. Exp Toxicol Pathol. 2011; 63: 69-78.

18. Wood CD, Thornton TM, Sabio G, et al. Nuclear localization of p38 MAPK in response to DNA damage. Int J Biol Sci. 2009; 5: 428-437.

19. Ghatan S, Larner S, Kinoshita Y, et al. p38 MAP kinase mediates bax translocation in nitric oxide-induced apoptosis in neurons. J Cell Biol. 2000;150: 335-347.

20 Gomez-Lazaro M, Galindo MF, Melero-Fernandez de Mera RM, et al. Reactive oxygen species and p38 mitogen-activated protein kinase activate Bax to induce mitochondrial cytochrome $\mathrm{c}$ release and apoptosis in response to malonate. Mol Pharmacol. 2007; 71: 736-743.

21. Lawrence NJ, McGown AT, Nduka J, et al. Cytotoxic Michael-type amine adducts of alpha-methylene lactones 
alantolactone and isoalantolactone. Bioor Med Chem Lett. 2001; 11: 429-431.

22. Konishi T, Shimada Y, Nagao T, et al. Antiproliferative sesquiterpene lactones from the roots of Inula helenium. Biol Pharm Bull. 2002; 25: 1370-1372.

23. Ding $X$, Zhu F, Li T, et al. Numb protects renal proximal tubular cells from puromycin aminonucleoside-induced apoptosis through inhibiting Notch signaling pathway. Int J Biol Sci. 2011; 7: 269-278.

24. Jia YT, Wei W, Ma B, et al. Activation of p38 MAPK by reactive oxygen species is essential in a rat model of stress-induced gastric mucosal injury. J Immunol. 2007;179: 7808-7819.

25. Tsujimoto $Y$, and Shimizu S. Role of the mitochondrial membrane permeability transition in cell death. Apoptosis. 2007; 12: 835-840.

26 Circu ML, and Aw TY. Reactive oxygen species, cellular redox systems, and apoptosis. Free Radic Biol Med. 2010; 48: 749-762.

27 Ji YB, Gao SY, Ji CF, et al. Induction of apoptosis in HepG2 cells by solanine and Bcl-2 protein. J Ethnopharmacol. 2008; 115: 194-202.

28 Ghatan S, Larner S, Kinoshita Y, et al. p38 MAP kinase mediates bax translocation in nitric oxide-induced apoptosis in neurons. J Cell Biol. 2000; 150: 335-347.

29. Hsu SC, Kuo CL, Lin JP, et al. Crude extracts of Euchresta formosana radix induce cytotoxicity and apoptosis in human hepatocellular carcinoma cell line (Hep3B). Anticancer Res. 2007; 27: 2415-2425.

30. Chiu TH, Lai WW, Hsia TC, et al. Aloe-emodin induces cell death through S-phase arrest and caspase-dependent pathways in human tongue squamous cancer SCC-4 cells. Anticancer Res. 2009; 29: 4503-4511.

31. Lopez-Lazaro M. Dual role of hydrogen peroxide in cancer: possible relevance to cancer chemoprevention and therapy. Cancer Lett. 2007; 252: 1-8.

32. Ho BY, Wu YM, Chang KJ, et al. Dimerumic acid inhibits SW620 cell invasion by attenuating HO-mediated MMP-7 expression via JNK/C-Jun and ERK/C-Fos activation in an AP-1-dependent manner. Int J Biol Sci. 2011; 7: 869-880.

33. Ding H, Han C, Guo D, et al. Selective induction of apoptosis of human oral cancer cell lines by avocado extracts via a ROS-mediated mechanism. Nutr Cancer. 2009; 61: 348-356. 